\title{
Xi Huang • Rory M. Marks \\ Use of receptors immobilized on microspheres to identify ligand binding sites in tissue sections: detection of lymph node ligands for L-Selectin
}

Accepted: 10 September 1996

\begin{abstract}
Particulate microspheres bearing immobilized probes can be used to identify ligands expressed by cells and require only brightfield microscopy for detection. There are distinct advantages to using microspheres to detect low affinity interactions; microspheres require no secondary amplification or detection procedures subsequent to the binding interaction, reducing opportunities for detachment of bound probe, and concentrating probes on microspheres may greatly increase binding avidity. Selectin leukocyte-endothelial adhesion molecules undergo low affinity binding to ligands, and these interactions may be difficult to detect with standard techniques. The aim of this study was to determine if immobilizing recombinant L-Selectin on microspheres would facilitate detection of specific tissue ligands. Microspheres were incubated with sections of rabbit peripheral lymph node in a modified Stamper-Woodruff assay, and binding was assessed by brightfield microscopy. L-Selectin-IgG microspheres bound to high endothelial venules, known to be sites of expression for L-Selectin ligands. Specificity was indicated by the lack of binding of microspheres coated with control protein, and inhibition of binding by antibody to L-Selectin and by competitive antagonists of L-Selectin ligand interactions.
\end{abstract}

\section{Introduction}

Microspheres bearing immobilized antibodies can be used to indicate the presence of antigen expressing cells (Gordon et al. 1977; Mirro et al. 1981). Similar studies have also used microspheres to identify other types of ligand-receptor interactions, such as between hormones and their cell surface receptors (Soda and Tavassoli 1983). This method requires minimal technology, and can be readily performed with standard brightfield mi-

X. Huang · R.M. Marks (

Department of Internal Medicine,

University of Michigan Medical School, Kresge I Building,

Room 4570, Ann Arbor, Michigan 48109-0531, USA

Tel. +1 313-936-3257; Fax +1 313-763-2025 croscopy by using microspheres large enough to be visualized. This approach has not, however, gained wide acceptance for histological and other studies, possibly due to the established utility of histochemical and fluorescence techniques that utilize soluble probes coupled with a wide range of secondary signal amplification and detection methods.

The use of microspheres to demonstrate receptor-ligand interactions may, however, offer distinct advantages in detecting low affinity interactions. These may be difficult to detect using established techniques that require multiple washes and incubations, during which non-avidly bound probe may detach. Using a microsphere-bound receptor eliminates this problem, as no signal amplification or detection steps are required; binding is assessed after a single brief wash to remove unbound microspheres. Immobilizing probes on microspheres may also facilitate detection by greatly increasing binding avidity through local increases in probe concentration (Harlow and Lane 1988).

The selectins are a three-member gene family of leukocyte-endothelial adhesion molecules (E-, L-, and P-Selectin) (Bevilacqua and Nelson 1993). Observations of leukocyte-endothelial interactions in in vitro, ex vivo, and in vivo models indicate that selectin-mediated interactions are responsible for an initial low affinity interaction, which results in the slowing of flow of leukocytes over microvascular endothelium (von Andrian et al. 1991; Lawrence and Springer 1991; Ley et al 1991). Selectin affinity has been estimated to be in the relatively low, $\mathrm{mM}^{-1}$, range (DeFrees et al. 1995; Green et al. 1995) based on studies with inhibitors of binding. Other adhesion molecules such as integrins are responsible for the subsequent high avidity adhesion that immobilizes leukocytes prior to endothelial transmigration (Lawrence and Springer 1991).

L-Selectin is constitutively expressed by all circulating leukocytes and binds to ligands expressed on vascular endothelium (Hallmann et al. 1991; Lewinsohn et al. 1987). Before L-Selectin was recognized as a selectin gene family member, it had been identified as a lympho- 
cyte homing receptor, responsible for the adhesion of lymphocytes to lymph node high endothelial venules (HEV) (Rosen 1993). HEV express at least three ligands for L-Selectin, glyCAM-1 (Lasky et al. 1992), CD34 (Baumhueter et al. 1993), and MadCam-1 (Berg et al. 1993). These molecules are all mucin-like glycoproteins that express functionally critical sulfated and sialylated carbohydrate structures that bind to the amino-terminal lectin domain of L-Selectin.

Identification of L-Selectin ligand binding in tissues has usually been performed by utilizing recombinant soluble forms of L-Selectin as affinity probes, followed by secondary signal amplification and detection techniques (Watson et al. 1990). Binding may be difficult to detect by this method, possibly due to the intrinsically low affinity character of the L-Selectin-ligand interaction. A variety of techniques have been used to facilitate detection of binding, including engineering polyvalent forms of L-Selectin, and chemical modification of the native ligand by periodate oxidation (Norgard et al. 1993). While ligand modification facilitates detection, it raises questions about the functional relevance of the native unmodified structures. A previous study used recombinant mouse L-Selectin conjugated to colloidal gold to identify mouse HEV ligands; however, a secondary enhancement procedure was required to detect binding at the light microscopic level with this method (Kikuta and Rosen 1994).

In order to study the pathobiology of L-Selectin in rabbit models of inflammation, we wanted to identify cells expressing L-Selectin ligands. Initially, a recombinant bivalent form of rabbit L-Selectin was used as a soluble affinity probe, and was combined with a standard immuno-enzymatic technique for signal amplification and detection. With this approach, no specific signal was detected in lymph node HEV, an expected site of L-selectin ligand expression. In contrast, after the same preparation of L-Selectin was immobilized on microspheres and used as a probe, specific binding was readily detected. This simple and practical technique enabled detection, histological localization, and quantitative assessment of L-Selectin ligand expression in lymph node $\mathrm{HEV}$. This strategy may also be useful to facilitate the detection of other low affinity receptor-ligand interactions in tissues.

\section{Materials and methods}

\section{Recombinant L-Selectin}

The rabbit L-Selectin cDNA (GenBank accession number U26535) was cloned from a rabbit cDNA library (Qian et al. 1996). The polymerase chain reaction (PCR) was utilized to amplify the region from the commencement of the mature translated peptide to the beginning of the trans-membrane domain, nucleotides 269-1153. Additional nucleotides were included in the sense strand oligonucleotide to provide an upstream NheI restriction site, enabling ligation in-frame with the signal peptide of CD5 already cloned into the plasmid vector. The sense strand oligonucleotide primer sequence was 5'-GCG CGG CTG CGG CTA GCG TGG
ACT TAC CAT TAT TCT GAA AAA CC-3'. Two oligonucleotide primers for the antisense strand were utilized sequentially for PCR in order to add additional sequence to the downstream region, encoding an in-frame heart muscle kinase target site (inserted to facilitate radiolabeling with ${ }^{32} \mathrm{P}$, but not utilized in this study), followed by a BamHI restriction site for ligation into the plasmid vector. The first antisense strand oligonucleotide primer had the sequence 5'-ACG ACG ACC TAC AGA TGC ACG TCG GGG GTT ATA GTC ACC CTC TT-3'. The second antisense strand oligonucleotide primer had the sequence $5^{\prime}$-TAT GTG CGG ATC CAC TGA TGC TCG ACG ACC TAC AGA TGC ACG TC-3'. PCR was initially performed with the sense strand oligonucleotide and the first antisense strand oligonucleotide. The PCR product was recovered by agarose gel electrophoresis and electroelution, and was used as the template for a second round of PCR, using the same sense strand oligonucleotide and the second antisense strand oligonucleotide. The PCR product was recovered and digested with restriction enzymes NheI and BamHI for ligation into plasmid vector pcDNA3 (Invitrogen, San Diego, Calif.) into which the cDNA for the signal peptide of CD5, and part of the constant region of the heavy chain of human $\mathrm{IgG}_{1}$ (hinge, $\mathrm{CH} 2, \mathrm{CH} 3$ region exons) had been ligated (Aruffo et al. 1990; Shao et al. 1994). Digestion of this plasmid with NheI and BamHI allowed the construct to be ligated in-frame downstream from sequence encoding the signal peptide of CD5 and upstream from sequence encoding the heavy chain of human $\operatorname{IgG}_{1}$. The fusion protein expressed by this construct was named L-Selectin-IgG.

\section{Cell culture and transfection}

293 cells are a permanent line of human embryonal kidney cells transformed by sheared human adenovirus type 5 (CRL1573, American Type Culture Collection, Rockville, Md.). Cells were grown in Dulbecco's modified Eagle's medium containing 10\% fetal bovine serum, $100 \mathrm{U} / \mathrm{ml}$ penicillin, and $100 \mu \mathrm{g} / \mathrm{ml}$ streptomycin (all from Gibco BRL, Gaithersburg, Md.). Cells were transfected by calcium phosphate coprecipitation (Opipari et al. 1992) and culture supernatant was collected after $72 \mathrm{~h}$. The supernatant was clarified by centrifugation, and stored at $-80^{\circ} \mathrm{C}$.

\section{Immobilization of L-Selectin on microspheres}

A 10-ml aliquot of culture supernatant from cells transfected with the L-Selectin- $\operatorname{IgG}$ construct was mixed in a rotator for $2 \mathrm{~h}$ at $4^{\circ} \mathrm{C}$ with $10 \mu \mathrm{l}$ blue-dyed polystyrene microspheres bearing covalently bound protein A, a staphylococcal-derived peptide that binds avidly to the Fc region of human $\mathrm{IgG}$ (Polysciences, Warrington, Pa.). Control microspheres were prepared by similar incubation with 10 $\mu \mathrm{g} / \mathrm{ml}$ normal human IgG (Sigma, St. Louis, Mo.) diluted in culture supernatant from non-transfected cells. Microspheres were sedimented by centrifugation at $250 \mathrm{~g}$, and unbound material removed by washing 3 times with $10 \mathrm{ml}$ phosphate-buffered saline (PBS, Gibco). Unless otherwise stated, PBS contained both calcium and magnesium. Coated microspheres were kept at $4^{\circ} \mathrm{C}$ until used. The amount of protein immobilized on the microspheres was quantitated after eluting bound protein from microspheres by boiling in $1 \% \mathrm{SDS} ; 3.2 \mathrm{fg}$ of L-Selectin-IgG and $3.6 \mathrm{fg}$ of IgG were bound per microsphere. Microsphere-immobilized L-Selectin-IgG was deglycosylated by incubation with $2 \times 10^{3} \mathrm{U}$ of PNGaseF (New England Biolabs, Beverly, Mass.) in $50 \mu 1$ of $50 \mathrm{mM}$ sodium phosphate $\mathrm{pH} 7.5,1 \%$ Nonidet P-40 (Sigma), for $1 \mathrm{~h}$ at $37^{\circ} \mathrm{C}$.

\section{Antibodies}

Antibodies to rabbit L-Selectin were generated against recombinant L-Selectin expressed in Escherichia coli, using the plasmid vector pGEX-KT (Hakes and Dixon 1992). Expressed protein did not contain any immunoglobulin sequence. A monoclonal $\mathrm{IgG}_{1}$ antibody was generated from immunized mice and used for west- 
ern blotting experiments. Polyclonal antibody was generated from immunized chickens, immunoglobulin was purified from egg yolks, and used for function-blocking experiments. Antibody recognition of native rabbit L-Selectin was validated by flow cytometry analysis of specific binding to fresh rabbit leukocytes and western blotting of rabbit leukocyte lysates.

\section{Western blotting}

Culture supernatants or microspheres were boiled in sample buffer containing $2 \%$ SDS, resolved by $5 \%$ or $10 \%$ sodium dodecyl sulfate polyacrylamide gel electrophoresis (SDS-PAGE) using a Laemmli buffer system (Laemmli 1970), and electro-transferred to nitrocellulose membrane (Schleicher and Scheull, Keene, N.H.) Membranes were blocked with 5\% non-fat dry milk in TRIS-buffered saline (TBS: $0.15 \mathrm{M} \mathrm{NaCl}, 20 \mathrm{mM}$ TRIS, pH 7.6). Human $\mathrm{IgG}$ epitopes were detected by incubating membranes with peroxidase-conjugated goat antibody to human IgG (BioRad, Hercules, Calif.), diluted 1/10 000 in blocking solution, for $1 \mathrm{~h}$ at room temperature. After washing, antibody binding was detected using an enhanced chemiluminescence kit (Amersham, Arlington Heights, Ill.). L-Selectin epitopes were detected by incubating membranes with $0.5 \mu \mathrm{g} / \mathrm{ml}$ mouse monoclonal antibody to rabbit L-Selectin for $1 \mathrm{~h}$ at room temperature, followed by goat antibody to mouse IgG (BioRad) diluted 1/10 000 for $1 \mathrm{~h}$ at room temperature, and antibody binding was detected as above. In all experiments control blots were probed with normal mouse $\operatorname{IgG}_{1}$ (Sigma).

\section{Tissue preparation}

Adult outbred 3-kg New Zealand White rabbits of either gender were maintained by the University of Michigan Unit for Laboratory Animal Medicine in accordance with a protocol approved by the Committee on Use and Care of animals. Lymph nodes were dissected from the axillae and anterior cervical chain of rabbits immediately following euthanasia. Tissue was snap-frozen in tissue freezing medium (Fisher Scientific, Pittsburgh, Pa.) in sublimated isopentane, $8-\mu \mathrm{M}$ sections cut in a cryostat, adhered to ProbeOn Plus microscope slides (Fisher Scientific), and stored at $-80^{\circ} \mathrm{C}$ until used.

\section{Binding assay}

Tissue sections were thawed and allowed to air dry in ambient conditions for $2 \mathrm{~h}$. Microspheres were diluted to $0.125 \% \mathrm{v} / \mathrm{v}$ in PBS and applied over the tissue in a total volume of $100 \mu \mathrm{l}$. Solution was retained in place by outlining the area of the tissue section with a hydrophobic marker. Sections were incubated on a platform rotating with a $75-\mathrm{mm}$ diameter circular moment in a horizontal plane at $60 \mathrm{rpm}$ for $60 \mathrm{~min}$ at $10^{\circ} \mathrm{C}$ (Belly Dancer rotating platform, Stovall Life Science, Greensboro, N.C.). The microsphere-containing solution was allowed to drain briefly from the sections onto blotting paper, placed vertically into a staining jar containing $4 \%$ glutaraldehyde in $0.1 \mathrm{M}$ cacodylate buffer (Electron Microscopy Sciences, Fort Washington, Pa.), and fixed overnight at $4{ }^{\circ} \mathrm{C}$. In preliminary experiments, we found that this initia chemical fixation was important to stabilize the specific microsphere-tissue interaction and it did not result in any increase in non-specific binding. Slides were washed twice by dipping vertically through an air-fluid interface into PBS, stained with nuclear fast red (Vector Laboratories, Burlingame, Calif.), and coverslipped using aqueous mountant for microscopic observation (Gel/Mount, Biomeda, Foster City, Calif.). Sections were assessed using brightfield illumination. Microsphere contrast was optimized by using the condenser to focus the light slightly below the tissue plane. For quantitative analysis, a minimum of 20 individual HEV structures in three tissue sections were assessed for numbers of associated microspheres. Results were expressed as frequency histograms, with ten-microsphere frequency intervals.
To assess the ability of inhibitors of selectin interactions to block L-Selectin-IgG microsphere binding to HEV, these reagents were co-incubated with microspheres during the binding assay. Cation dependence was tested by comparing binding in PBS with calcium and magnesium $\left(0.1 \mathrm{~g} / \mathrm{l} \mathrm{CaCl} 2,0.1 \mathrm{~g} / \mathrm{l} \mathrm{MgCl}_{2} \cdot 6 \mathrm{H}_{2} \mathrm{O}\right)$, to binding in calcium- and magnesium-free PBS supplemented with $10 \mathrm{mM}$ EDTA. Polyclonal chicken antibody to rabbit L-Selectin and control normal chicken IgY (Lampire Biological Laboratories, Pipersville, $\mathrm{Pa}$.) were used at $1 \mathrm{mg} / \mathrm{ml}$, phosphomannan core monoester (PPME, gift of C. R. Parish, Australian National University) was used at $10 \mu \mathrm{g} / \mathrm{ml}$, and the concentration of sulfatides (Sigma) applied was $100 \mu \mathrm{g} / \mathrm{ml}$.

\section{Immunohistochemistry}

Immunohistochemical assessment of binding of soluble L-Selectin-IgG to lymph node sections was carried out exactly according to the manufacturer's instructions (Vector Laboratories, ABC-AP kit), using lymph node sections prepared as described above. LSelectin-IgG and control human IgG were applied at concentrations from 1 to $20 \mu \mathrm{g} / \mathrm{ml}$. Goat antibody to rabbit thrombomodulin (gift of N. Esmon, Oklahoma Medical Research Foundation) binds vascular endothelial cells and was used as a positive control to identify the lymph node microvasculature, and to validate the immunohistochemistry test reagents. Purified immunoglobulin applied at $1 \mu \mathrm{g} / \mathrm{ml}$ provided optimal tissue staining.

\section{Results}

\section{Expression of recombinant soluble L-Selectin-IgG}

The protein coding region of rabbit L-Selectin was subcloned as an amino-terminal fusion with part of the constant region of the heavy chain of human IgG. Recombinant L-Selectin-IgG was identified by western blotting in culture supernatants $72 \mathrm{~h}$ following transfection of 293 cells. Figure 1a demonstrates the results of resolving culture supernatants by $10 \%$ SDS-PAGE in reducing conditions, followed by blotting with antibodies to rabbit LSelectin and human IgG; the results indicate that transfection is associated with secretion of a protein of molecular weight $8.1 \times 10^{4}$ Da expressing both rabbit L-Selectin and human IgG epitopes. Western blotting of nontransfected culture supernatant with antibody to L-Selectin did not identify any protein band, and probing duplicate blots with normal control immunoglobulins was also negative (not shown). PAGE performed under non-reducing conditions in $5 \%$ polyacrylamide gels, followed by western blotting with antibody to human $\mathrm{IgG}$, resulted in identification of a predominant peptide with molecular weight $1.6 \times 10^{5} \mathrm{Da}$ (Fig. 1b), indicating that the recombinant L-Selectin-IgG was secreted as a homodimer, as expected for a molecule incorporating disulfide-linked IgG heavy chain determinants.

The peptide sequence of the L-Selectin-IgG construct has a predicted molecular weight of $6.04 \times 10^{4} \mathrm{Da}$, indicating that a post-translational modification such as glycosylation had occurred to account for the additional molecular weight observed. To investigate this, L-SelectinIgG was treated with the endoglycosidase, PNGaseF, which cleaves all classes of $N$-linked carbohydrate chains at the peptide-carbohydrate linkage (Elder and 


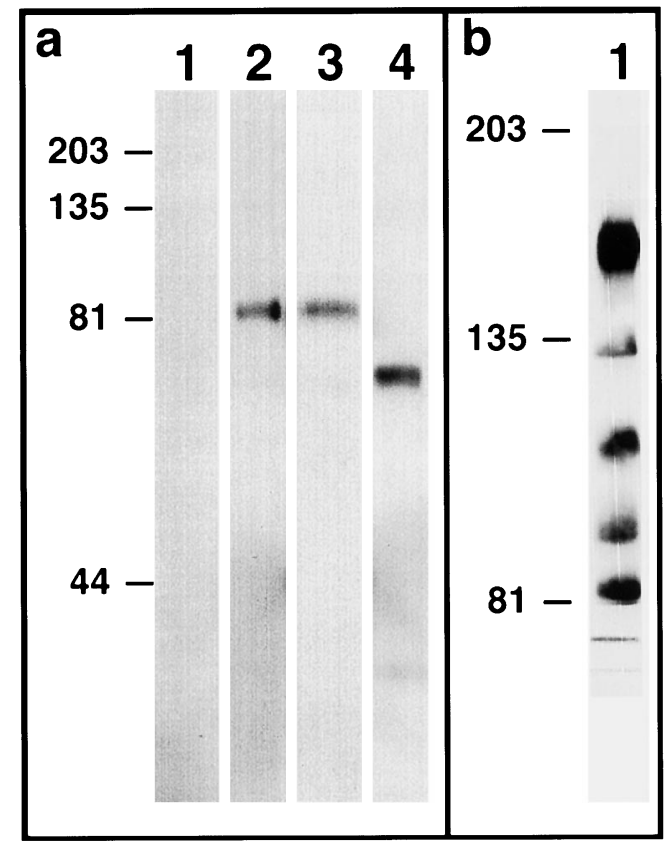

Fig. 1a, b Western blotting analysis of recombinant L-SelectinIgG. a Culture supernatants $(50 \mu \mathrm{l})$ from 293 cells were electrophoresed through $10 \%$ SDS-PAGE gels in reducing conditions and western blotted. Lane 1 Untransfected 293 cells probed with antibody to L-Selectin. Lane 2293 cells transfected with L-SelectinIgG cDNA, and probed with antibody to L-Selectin. Lane 3293 cells transfected with L-Selectin-IgG cDNA, and probed with antibody to human IgG. Lane $4 \mathrm{~L}$-Selectin-IgG captured from culture supernatant by binding to protein A microspheres, treated with PNGaseF before electrophoresis, and probed with antibody to LSelectin. Numbers at the left refer to the position of molecular weight markers $\left(\times 10^{-3} \mathrm{Da}\right)$. b Lane 1 Culture supernatant $(50 \mu \mathrm{l})$ from 293 cells transfected with L-Selectin-IgG cDNA, electrophoresed through a $5 \%$ polyacrylamide gel in non-reducing conditions, and western blotted with antibody to human IgG. Numbers at the left refer to the position of molecular weight markers $\left(\times 10^{-3} \mathrm{Da}\right)$

Alexander 1982). Fig. 1a demonstrates that digestion of L-Selectin-IgG with PNGaseF caused a reduction in molecular weight from $8.1 \times 10^{4} \mathrm{Da}$ to the predicted $6 \times 10^{4} \mathrm{Da}$, indicating that the entire difference in molecular weight was due to $N$-linked glycosylation.

\section{L-Selectin-IgG immunohistochemistry}

In initial experiments, the soluble L-Selectin-IgG was used in combination with a standard immunohistochemical signal amplification technique for detection of tissue ligand binding; these experiments failed to display any convincing positive signal (not shown). The technique chosen required sequential binding of a biotinylated secondary antibody, a complex of avidin-biotin-alkaline phosphatase, and color development with an insoluble chromogen. This procedure was validated by testing for detection of thrombomodulin, using adjacent tissue sections incubated with an antibody to rabbit thrombomodulin; these assays demonstrated the expected pan- vascular color development (not shown). In addition, the secondary antibody and all other immunohistochemistry reagents were successfully used to detect specific binding of another IgG chimera recombinant soluble receptor protein to cultured endothelial cells. Thus, all detection reagents used were validated in other systems.

\section{Microsphere binding to lymph node HEV}

The method used by Stamper and Woodruff (1976) to assess binding of lymphocytes to HEV was adapted for binding of microspheres to HEV in lymph node sections. Incubation of microspheres over tissue sections with constant rotation generated binding of L-Selectin- $\mathrm{IgG}$ microspheres to HEV, with minimal non-specific binding. Figure 2 presents photomicrographs of lymph node sections exposed to L-Selectin-IgG or control IgG microspheres. Figure 2a depicts L-Selectin-IgG microspheres bound to the surface of an HEV, seen in longitudinal section; Fig. $2 b$ demonstrates that in an HEV from a section exposed to control IgG microspheres, none are bound. Figure $2 \mathrm{c}$ is a lower power view of L-SelectinIgG microspheres bound to the same longitudinally sectioned HEV presented in Fig. 2a; it demonstrates that the microspheres are bound only in the vicinity of the HEV and not to surrounding cells. Figure $2 \mathrm{~d}$ demonstrates LSelectin-IgG microspheres bound to an HEV seen in cross section; Fig. 2e demonstrates that in a serial section of the same HEV exposed to control IgG microspheres, none are bound.

Quantitative data were obtained by counting numbers of microspheres bound per individual HEV, and the results were expressed as frequency histograms. Figure 3 shows the frequency distribution of binding of L-Selectin-IgG microspheres to HEV, compared with binding of control IgG microspheres, and confirms that HEV binding occurs only with L-Selectin-IgG microspheres.

\section{Inhibition of binding}

Selectin-ligand interactions are cation-dependent. To further evaluate the specificity of the interaction of L-Selectin-IgG microspheres and HEV ligands, the cation dependence of binding was examined. Microsphere binding to HEV in calcium- and magnesium-containing buffer was compared with binding in cation-free buffer supplemented with the cation chelator, EDTA. The results are expressed as frequency histograms of microspheres per $\mathrm{HEV}$, and indicate that the L-Selectin-IgG microsphere interaction with HEV is cation-dependent (Fig. 4a).

A polyclonal chicken antibody to rabbit L-Selectin was used to confirm that HEV binding was dependent on L-Selectin epitopes. This antibody was generated against prokaryotic recombinant L-Selectin lacking any human immunoglobulin sequence; it binds to native and recombinant rabbit L-Selectin, but not to rabbit endothelial cells activated to express E- or P-Selectin. L-Selectin- 

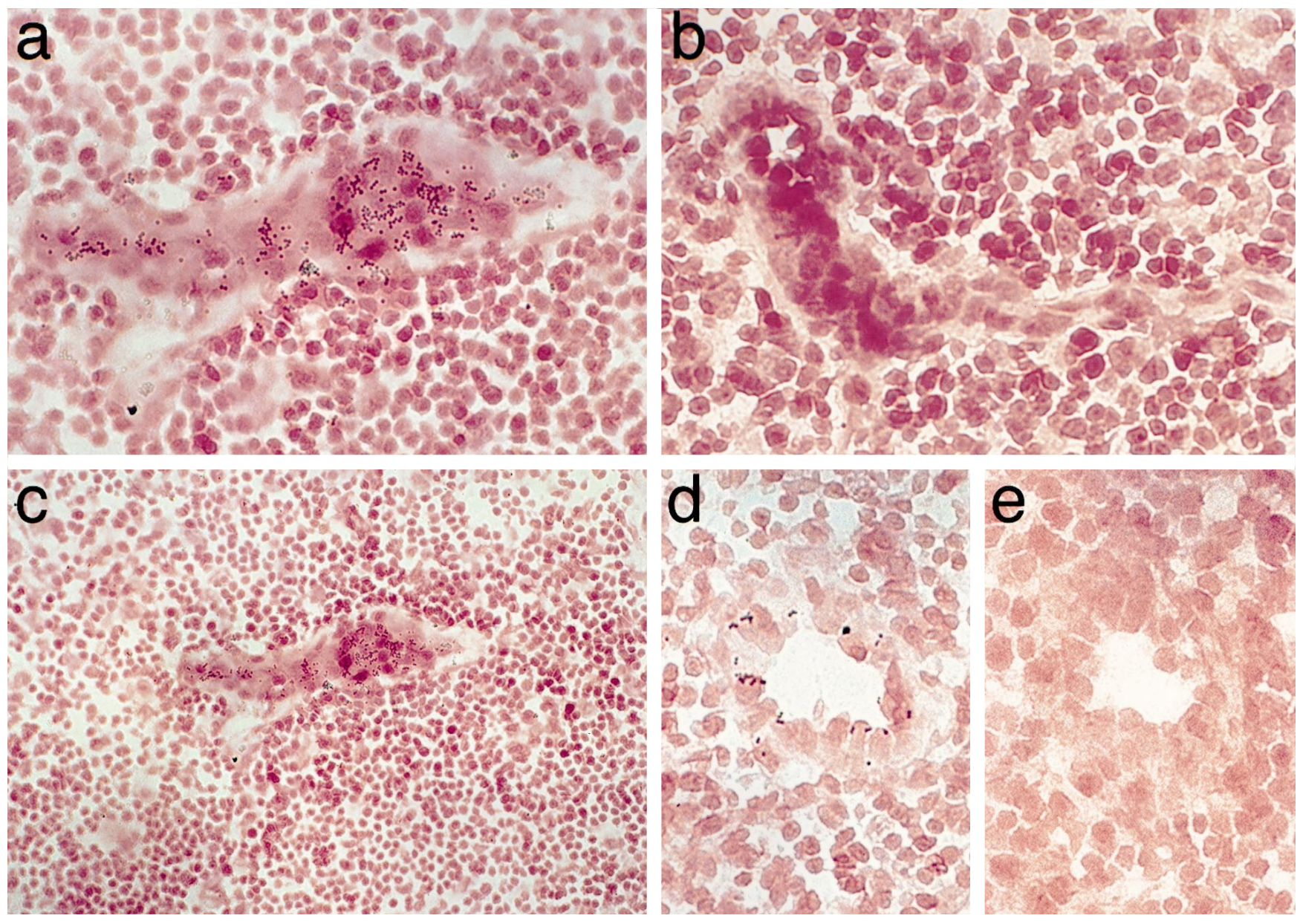

Fig. 2a-e Photomicrographs of sections of rabbit peripheral lymph node demonstrating specific microsphere binding to high endothelial venules (HEV). Sections were exposed to microspheres coated with L-Selectin-IgG or control human IgG, fixed and washed, and counterstained with nuclear fast red before observation under brightfield illumination. a L-Selectin-IgG microspheres bound to the surface of an HEV cut in longitudinal section $(\times 320)$. b HEV cut in longitudinal section, and exposed to control IgG microspheres $(\times 400)$. There is no microsphere binding. c LSelectin-IgG microspheres bound to the surface of the same HEV as in $\mathbf{a}$ at lower magnification $(\times 120)$, demonstrating the lack of microsphere binding to non-HEV cells. d L-Selectin-IgG microspheres bound to an HEV cut in cross section $(\times 360)$. e Serial section of same HEV illustrated in d exposed to control IgG microspheres $(\times 360)$. There is no microsphere binding to HEV or other cells

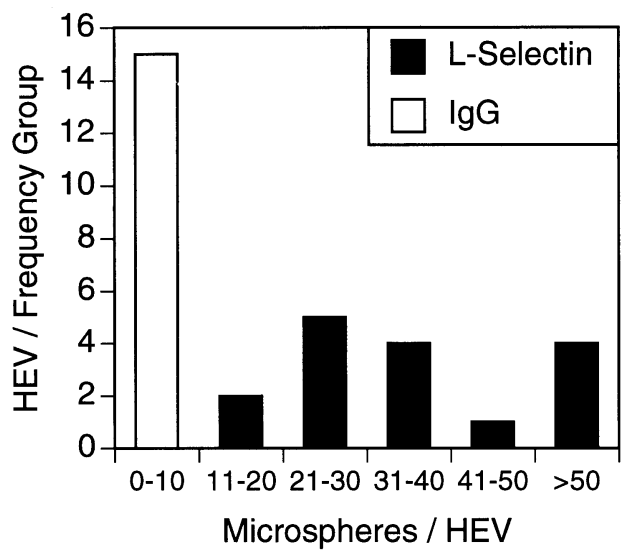

IgG microspheres incubated with normal chicken $\operatorname{IgY}$ displayed the expected HEV binding, while L-SelectinIgG microspheres incubated with antibody to L-Selectin did not bind HEV (Fig. 4b).

The HEV ligands for L-Selectin are mucin-like glycoproteins that express functionally critical sulfate, fucose, and sialic acid moieties (Rosen 1993). Sulfated, fucosylated, and sialylated macromolecules have been used as competitive antagonists of L-Selectin binding to ligands (Lewinsohn et al. 1987; Suzuki et al. 1993; Yoshida et al. 1994), presumably mimicking crucial characteristics of the natural ligands. Two of these molecules,

Fig. 3 Frequency histogram comparing numbers of L-SelectinIgG and control IgG microspheres bound per peripheral lymph node HEV. Sixteen randomly chosen HEV structures in three tissue sections incubated with L-Selectin IgG microspheres and 15 HEV in three tissue sections incubated with control IgG microspheres were assessed for numbers of bound microspheres. Results were expressed as frequency histograms, with ten-microsphere frequency intervals. Abscissa Frequency groups for number of microspheres found associated with each HEV. Ordinate Number of HEV in each frequency group. Solid columns L-Selectin$\mathrm{IgG}$ microspheres, open columns control IgG microspheres 


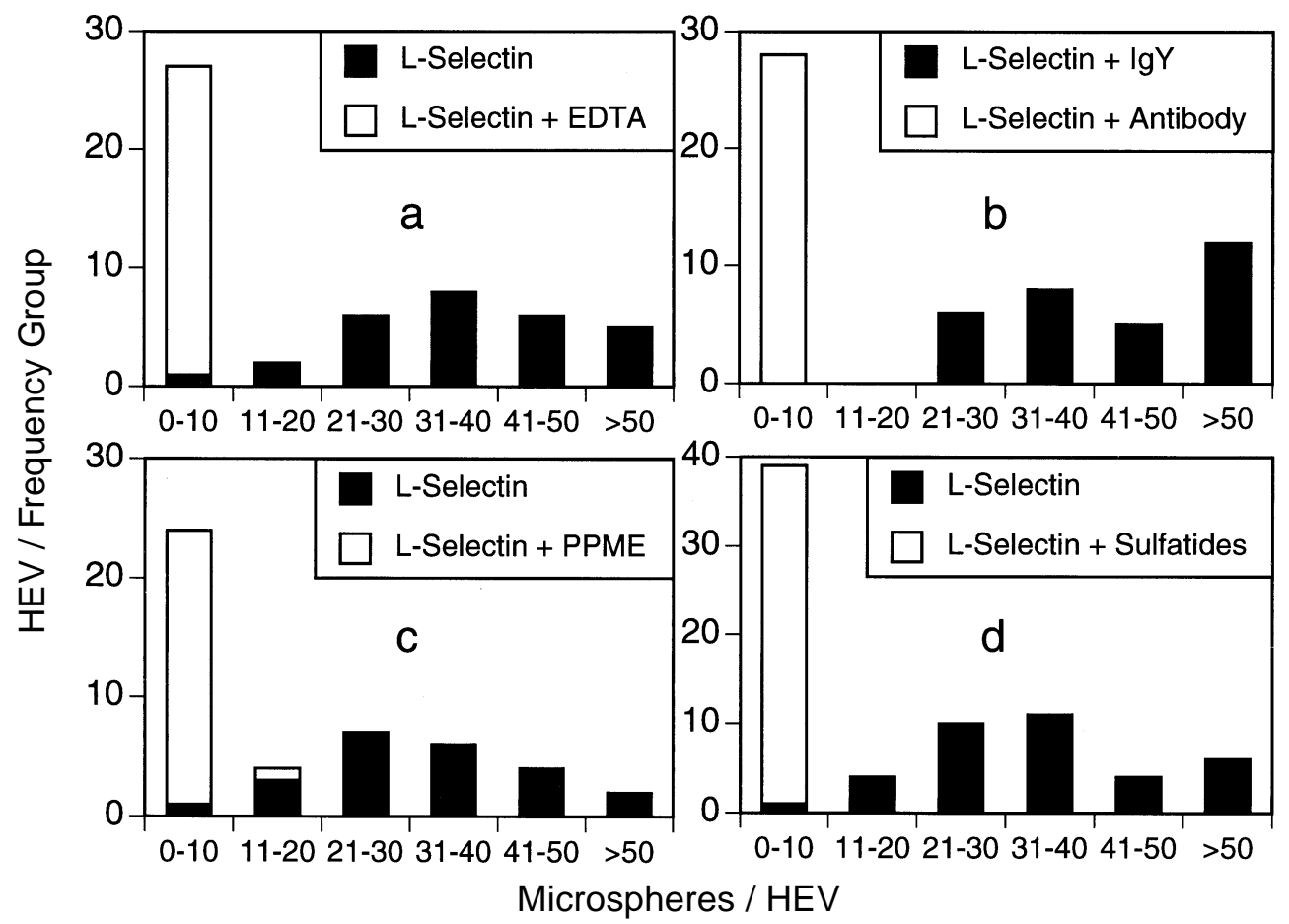

Fig. 4a-d Effect of selectin inhibitors on L-Selectin-IgG microsphere binding to peripheral lymph node HEV, expressed as frequency histograms of numbers of microspheres bound per HEV. Three serial lymph node sections were incubated with L-SelectinIgG microspheres, and replicates incubated with L-Selectin-IgG microspheres in the presence of inhibitor. A minimum of 20 individual HEV structures in three sections were assessed for numbers of associated microspheres. Results were expressed as frequency histograms, with ten-microsphere frequency intervals. Abscissa Frequency groups for number of microspheres found associated with each HEV. Ordinate Number of HEV in each frequency group. a Cation requirement. L-Selectin-IgG microspheres incubated over lymph node sections in cation-containing buffer (solid columns), and cation-free buffer with EDTA (open columns). b LSelectin antibody. L-Selectin-IgG microspheres incubated over sections in the presence of polyclonal chicken antibody to rabbit L-Selectin (open columns) or with control chicken IgY (solid columns). c Phosphomannan core monoester (PPME). L-Selectin-IgG microspheres incubated over sections in the presence (open columns) or absence (solid columns) of PPME. d Sulfatides. L-Selectin-IgG microspheres incubated over sections in the presence (open columns) or absence (solid columns) of sulfatides

PPME, and sulfatides were found to significantly inhibit binding of L-Selectin-IgG microspheres to $\mathrm{HEV}$ (Fig. 4c, d).

\section{Discussion}

Our data demonstrate that L-Selectin-IgG microspheres can be used to identify cells expressing L-Selectin ligands in tissue sections. Initial experiments using a soluble recombinant form of L-Selectin and a standard immunohistochemical technique failed to demonstrate the expected binding to lymph node $\mathrm{HEV}$, possibly due to the low affinity binding of rabbit L-Selectin to its li- gands. In contrast, immobilization of L-Selectin on microspheres enabled consistent detection of a L-Selectinspecific interaction with HEV.

While it is not possible to manipulate receptor-ligand affinity, it is possible to modulate the avidity of receptorligand interactions. Avidity is defined as the overall stability of an interaction, and relates to factors that include affinity, but it is also markedly influenced by local concentrations of probe and the possibility of multivalent binding. Low affinity interactions may be prone to dissociation; however, a high local concentration of receptor increases the chance that any dissociated ligand will immediately rebind to a neighboring receptor. Immobilizing the bivalent recombinant L-Selectin-IgG probe on microspheres generated high local concentrations of LSelectin, which essentially acted as a trap to hold the ligand to the solid phase. Further, the $1-\mu \mathrm{m}$ diameter microspheres were large enough to be resolved by standard brightfield light microscopy; thus, the signal amplification and detection steps, which are components of most immunohistochemical protocols, were not required. These steps entail multiple prolonged washes and incubations in the absence of free probe, which in the case of a low affinity interaction might result in detachment of bound probe and loss of signal.

L-Selectin-IgG was coupled to microspheres by binding its carboxy-terminal $\mathrm{Fc}$ region to protein $\mathrm{A}$, which had previously been covalently immobilized on the surface of the microspheres. This allowed the amino-terminal L-Selectin domains to be uniformly directed externally, optimizing opportunities for ligand binding. The protein A-Fc interaction is of such high affinity that it is essentially non-dissociable under physiological conditions (Goding 1978). Thus, coupling did not require any 
chemical crosslinking procedure involving the L-Selectin-IgG molecule, which could have affected ligand binding. The same protein A microspheres could also be used to detect tissue antigens by binding to any antibody with a suitable Fc region. Alternatively, any antibody could be directionally immobilized, through anti-immunoglobulins bound to microspheres. In addition, a wide range of alternative coupling techniques are available from suppliers of microspheres, and essentially any soluble recombinant protein probe could be immobilized on microspheres by direct chemical crosslinking.

Microsphere binding can be readily quantitated by counting numbers of microspheres per target structure and we have demonstrated that frequency histograms allow the effects of interventions to be compared. Fluorochrome-impregnated microspheres are available and could be utilized for operator-independent morphometrics.

Relatively large microspheres $(1-\mu \mathrm{m}$-diameter) were utilized in this study to allow detection by brightfield microscopy. This may have limited detection sensitivity due to failure to penetrate below the surface of the sectioned tissue. It is possible that the use of smaller particles, incorporating, for example, a fluorochrome to facilitate detection, would lead to even greater sensitivity.

No expensive technology is required for this technique beyond the standard brightfield microscope available to most laboratories, and no expensive signal amplification and detection kits need to be purchased. Suitable microspheres are commercially available, are relatively inexpensive, and are stable indefinitely. The use of receptor-immobilized microspheres, in addition to its demonstrated utility in probing low-affinity selectin interactions with tissue ligands, may well be a sensitive method for localizing and quantitating other types of receptor-ligand and antigen-antibody binding interactions.

Acknowledgements Dr. Marks is supported by US Public Health Service Grants PO1AI331890004, P50AR417030003, MO1RR000420758, and P60AR20557.

\section{References}

Andrian UH von, Chambers JD, McEvoy LM, Bargatze RF, Arfors K-E, Butcher EC (1991) Two-step model of leukocyte-endothelial cell interactions in inflammation: distinct roles for LECAM-1 and the leukocyte $\beta 2$ integrins in vivo. Proc Natl Acad Sci USA 88:7538-7542

Aruffo A, Stamenkovic I, Melnick M, Underhill CB, Seed B (1990) CD44 is the principal cell surface receptor for hyaluronate. Cell 61:1303-1313

Baumhueter S, Singer MS, Henzel W, Hemmerich S, Renz M, Rosen SD, Lasky LA (1993) Binding of L-Selectin to the vascular sialomucin CD34. Science 262:436-438

Berg EL, McEvoy LM, Berlin C, Bargatze RF, Butcher EC (1993) L-Selectin mediated rolling on MadCAM-1. Nature 366:695698

Bevilacqua MP, Nelson RM (1993) Selectins. J Clin Invest 91: 379-387
DeFrees SA, Kosch W, Way W, Paulson JC, Sabesan A, Halcomb RL, Huang D-H, Ichikawa Y, Wong C-H (1995) Ligand recognition by E-Selectin: synthesis, inhibitory activity, and conformational analysis of bivalent sialyl lewis $x$ analogs. J Am Chem Soc 117:66-79

Elder JH, Alexander S (1982) Endo-beta- $N$-acetylglucosaminidase F: endoglycosidase from Flavobacterium meningosepticum that cleaves both high-mannose and complex glycoproteins. Proc Natl Acad Sci USA 79:4540-4544

Goding JW (1978) Use of staphylococcal protein A as an immunological reagent. J Immunol Methods 20:241-253

Gordon IL, Dreyer WJ, Yen SPS, Rembaum A (1977) Light microscope identification of murine $\mathrm{B}$ and $\mathrm{T}$ cells by means of functional polymeric microspheres. Cell Immunol 28:307324

Green PJ, Yuen C-T, Childs RA, Chai W, Miyasaka M, Lemoine R, Lubineau A, Smith B, Ueno H, Nicolaou KC, Feizi T (1995) Further studies of the binding specificity of the leukocyte adhesion molecule, L-Selectin, towards sulphated oligosaccharides - suggestion of a link between the selectin- and the integrin-mediated lymphocyte adhesion systems. Glycobiology 5:29-38

Hakes DJ, Dixon JE (1992) New vectors for high level expression of recombinant proteins in bacteria. Anal Biochem 202:293298

Hallmann R, Jutila MA, Smith CW, Anderson DC, Kishimoto TK, Butcher EC (1991) The peripheral lymph node homing receptor, LECAM-1, is involved in CD18-independent adhesion of human neutrophils to endothelium. Biochem Biophys Res Commun 174:236-243

Harlow E, Lane D (1988) Antibody-antigen interactions. In: Antibodies: a laboratory manual. Cold Spring Harbor Laboratory Press, Cold Spring Harbor, NY, chapter 3

Kikuta A, Rosen SD (1994) Localization of ligands for L-selectin in mouse peripheral lymph node high endothelial cells by colloidal conjugates. Blood 84:3766-3775

Laemmli UK (1970) Cleavage of structural proteins during the assembly of the head of bacteriophage T4. Nature 227:680 685

Lasky LA, Singer MS, Dowbenko D, Imai Y, Henzel WJ, Grimley C, Fennie C, Gillett N, Watson SR, Rosen SD (1992) An endothelial ligand for L-selectin is a novel mucin-like molecule. Cell 69:927-938

Lawrence MB, Springer TA (1991) Leukocytes roll on a selectin at physiologic flow rates: distinction from and prerequisite for adhesion through integrins. Cell 65:859-873

Lewinsohn DM, Bargatze RF, Butcher EC (1987) Leukocyte-endothelial cell recognition: evidence of a common molecular mechanism shared by neutrophils, lymphocytes, and other leukocytes. J Immunol 138:4313-4321

Ley K, Gaehtgens P, Fennie C, Singer MS, Lasky LA, Rosen SD (1991) Lectin-like cell adhesion molecule 1 mediates leukocyte rolling in mesenteric venules in vivo. Blood 77:25532555

Mirro J, Schwartz JF, Civin CI (1981) Simultaneous analysis of cell surface antigens and cell morphology using monoclonal antibodies conjugated to fluorescent microspheres. J Immunol Methods 47:39-48

Norgard KE, Han H, Powell L, Kriegler M, Varki A, Varki NM (1993) Enhanced interaction of L-selectin with the high endothelial venule ligand via selectively oxidized sialic acids. Proc Natl Acad Sci USA 90:1068-1072

Opipari AW Jr, Hu HM, Yabkowitz R, Dixit VM (1992) The A20 zinc finger protein protects cells from tumor necrosis factor cytotoxicity. J Biol Chem 267:12424-12427

Qian J, Xi H, Marks RM (1996) Cloning of the cDNA for rabbit L-Selectin and expression of recombinant protein with a kinase target site to facilitate radiolabeling. Biochem Biophys Res Commun 225:406-412

Rosen SD (1993) L-Selectin and its biological ligands. Histochemistry 100:185-191 
Shao H, Lou L, Pandey A, Pasquale EB, Dixit VM (1994) cDNA cloning and characterization of a ligand for the Cek5 receptor protein-tyrosine kinase. J Biol Chem 269:26606-26609

Soda R, Tavassoli M (1983) Distribution of insulin receptors in liver cell suspensions using a minibead probe. Highest density is on endothelial cells. Exp Cell Res 145:389-395

Stamper HB Jr, Woodruff JJ (1976) Lymphocyte homing into lymph nodes: in vitro demonstration of the selective affinity of recirculating lymphocytes for high-endothelial venules. J Exp Med 144:828-833

Suzuki Y, Toda Y, Tamatani T, Watanabe T, Suzuki T, Nakao T, Murase K, Kiso M, Hasegawa A, Tadano-Aritomi K, Ishizuka
I, Miyasaka M (1993) Sulfated glycolipids are ligands for a lymphocyte homing receptor, L-Selectin (Lecam-1), binding epitope in sulfated sugar chain. Biochem Biophys Res Commun 190:426-434

Watson SR, Imai Y, Fennie C, Geoffroy JS, Rosen SD, Lasky LA (1990) A homing receptor-IgG chimera as a probe for adhesive ligands of lymph node high endothelial venules. J Cell Biol 110:2221-2229

Yoshida T, Toyama-Sorimachi N, Miyasaka M, Lee YC (1994) A crucial effect of ligand clustering on the inhibition of binding by L-Selectin in intercellular adhesion. Biochem Biophys Res Commun 204:969-974 